\title{
APPLICATION OF VALUE ENGINEERING IN AFFORDABLE HOUSING IN INDIA
}

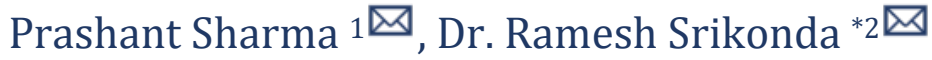 \\ ${ }^{1}$ Post Graduate Student, Department of Architecture, School of Planning and Architecture, \\ Vijayawada, Andhra Pradesh 520008, India \\ ${ }^{*} 2$ Professor, Department of Architecture, School of Planning and Architecture, Vijayawada, Andhra \\ Pradesh 520008, India
}

DOI: https://doi.org/10.29121/ijetmr.v8.i2.2021.865

Article Citation: Prashant Sharma, and Dr. Ramesh Srikonda. (2021). APPLICATION OF VALUE ENGINEERING IN AFFORDABLE HOUSING IN INDIA. International Journal of Engineering Technologies and Management Research, 8(2), 29-40.

https://doi.org/10.29121/ijetmr.v8 .i2.2021.865

Published Date: 17 February 2021

Keywords:

Value Engineering

Value Management

Value Analysis

Affordable Housing

Construction Management

\section{ABSTRACT}

A major challenge for the Indian government is the rapid growth of the urban population, leading to housing shortages and poor urban living conditions. The current need-based housing shortage in the country is about 19 million units as per the 2011 census. The government has introduced many affordable housing schemes that focus on meeting the shortage of housing needs. Excess cost management needs to be planned from the initial stages of design during the building's project life. Value engineering is an effective problem-solving approach that minimizes prices while preserving and improving performance and quality requirements. Ve process's success lies in its ability to find ways to reduce redundant expenses while maintaining efficiency, reliability, performance, and other critical elements that reach or surpass the standards of the client. This study aims at understanding the application of value engineering in affordable housing to optimize cost, time and quality thus increasing overall value of the project. Two case studies of different scale of housing projects are considered, it has been found out that on replacing a material with similar functions, helps reduce the cost of the project and add to the value of the project. This research will provide an overview of benefits of strong value engineering and use of alternative materials to enhance the efficiency of a project.

\section{INTRODUCTION}

The measure of a nation's development is the construction industry. With the liberalization of the economy, there is a significance growth of real estate in India. Today, after agriculture, the employer of skilled and semi-skilled labor construction industry is the second largest and plays a significant part in the economy of the country. The demand for housing space has also increased due to an increase in employment opportunities and labor migration. A major challenge for the Indian government is the rapid growth of the urban population, leading to housing shortages and poor urban living conditions. The current need-based housing shortage in the country is about 19 million units as per 2011 census, according to the twelfth five-year plan. Government has introduced many affordable housing schemes that focuses on meeting the shortage of housing needs.

In general, affordable housing is defined to be housing that satisfy the needs of households whose earnings are inadequate to give those access to affordable housing market. Decent housing is generally recognized as one of the

(C) 2021 The Author(s). This is an open access article distributed under the terms of the Creative Commons Attribution License, which permits unrestricted use, distribution, and reproduction in any medium, provided the original author and source are credited. 
essential needs of people, families, and the environment. A widely recognized criterion for affordable housing in the America and Canada is that housing costs should not exceed 30 percentage of the gross-income of a family. Housing expenses include owners' taxes, insurance, service expenses (cited in vibrant Gujarat, 2017). Housing affordability, which is taken as a measure of housing expenses on household returns, is considered one of the recognized concepts of affordability. This is also recognized by the Indian government, which specifies that' affordable housing applicable to any housing that satisfies any form of affordability requirement, which may be the amount of household income, the number of housing units or affordability in terms of EMI size or house price to annual income ratio.

Current economic circumstances have included the practice of coherent methods and techniques, the analysis and implementation of new techniques through the use of technical innovations in the manufacturing industry as well as in other fields. Excess cost management needs to be planned from the initial stages of design during the building's project life. To achieve optimal costs, it is necessary to scrutinize the project well and consider all feasible alternatives. Value engineering is a managing strategy which finds the finest practical combination among cost, quality and performance for a product, operation, process or service. VE is an effective problem-solving approach which minimises prices while preserving and improving performance and quality requirements. VE will enhance decision making, resulting in optimum owner fund investment while meeting the necessary level of function and quality. The ve process's success lies in its ability to find ways to reduce redundant expenses while maintaining efficiency, reliability, performance and other critical elements that reach or surpass standards of the client.

\subsection{OBJECTIVES}

- To understand the implementation of value engineering in affordable housing in India.

- To identify certain parameters by using this methodology how time, cost, and quality can be optimized.

\subsection{AIM}

This study aims to understand the application of value engineering in affordable housing to optimise cost, time and quality.

\subsection{RESEARCH QUESTIONS}

- How cost, time and quality of a project can be optimised using value engineering?

- What is the role of value engineering in different phases of construction?

\subsection{SCOPE}

The study focuses on the applicability of value engineering methodologies in the construction of affordable housing.

\section{LITERATURE STUDY}

\subsection{VALUE ENGINEERING}

Value engineering is an organized, creative, cost search technique for analyzing the function of a product with the purpose of value enhancement without compromising with its quality, performance and efficiency. It is a systematic process that seeks to achieve value for money at the lowest cost possible, consistent with required level of quality and performance. The main focus of Value Engineering is on improving the function, reducing the cost of the product, or both by the way of product evaluation and analysis.

Value $=\underline{\text { Function (desired performance) }}$ Cost 
Value engineering not only involves lowering the cost of processes and methods but also analysis of the function of a product. VE is a systematic approach directed towards purpose of analyzing system, equipment, facilities, staff and services for the purpose of achieving their desired functions low cost with required quality. Implementation of VE on any project leads to increased performance, quality and efficiency. The success of existing value engineering programs indicates that the same application to interior projects can be an opportunity for saving costs and better performance.in today's time of reduced budgets, cost cuts and staffing problems we can no longer afford untimely delays in projects and increased costs. When a project costs more than what was initially planned decision makers are forced to take tough decision with regards to the projects.

\subsection{VALUE ENGINEERING HISTORY}

The practice of VE has flourished for almost an era [1], with its roots in general electric during World War 2, when invention was needed due to resource scarcity. It was hard to procure some essential materials and several substitutions had to be made. The vice president, Harry Erlicker, noted that these improvements have resulted in lower prices and better goods several times. This inspired him to look for an approach to deliberately maximize the value of a commodity. He assigned the job of discovering a more proficient way to improve value of product to Lawrence d. Miles, an engineer [2].

In 1947, a method called value analysis (va) was developed by miles and his team to measure the cost of the product and work to minimize unnecessary expense. The new methodology was enhanced, analysed, and confirmed to be highly successful as a consequence of considerable investment. In 1952, va started its industry-wide production.

\subsection{VE DEFINITIONS AND FEATURES}

The numerous specialists and practitioners of this method have a multitude of interpretations, and few are mentioned below:

- [3]"a discipline action system, attuned to one specific need: accomplishing the functions that the customer needs and wants at the lowest cost".

- [4]). "a validated management strategy using a structured approach to find the best practical balance between the expense, efficiency and quality of the project,".

- Connaught on and green (1996) "a systematic approach to delivering the required functions at lowest cost without detriment to quality, performance and reliability".

- Hayles and simister (2000) "proactive, creative, team approach to problem-solving in construction projects to provide the best value for money".

- [5] VE can be characterized as a coordinated, systemic, comprehensive approach to problem-solving basically focused on evaluating role of processes, machinery, amenities, resources, and materials for the need to perform their vital roles with the necessary efficiency, durability, quality, and safety at the lowest life-cycle capital expenditure.

- [6], described VE as it is an innovative and well-organized mechanism that aims at providing the user with consistent chance to save costs without damaging key functions or results. 


\subsection{INTRODUCTION OF VALUE ENGINEERING IN INDIA}

\begin{tabular}{|l|l|}
\hline Year & \multicolumn{1}{c|}{ Development } \\
\hline 1977 & $\begin{array}{l}\text { The Indian Value Engineering Society (INVEST) was founded in October. First national } \\
\text { Conference held in New Delhi. }\end{array}$ \\
\hline 1981 & 2nd INVEST National Conference, New Delhi. \\
\hline 1982 & $\begin{array}{l}\text { 3rd INVEST National Conference, Bangalore. And Invest Eastern Zonal Chapter inaugurated, } \\
\text { at Jamshedpur. }\end{array}$ \\
\hline 1983 & 4th INVEST National Conference, New Delhi. \\
\hline 1984 & 5th INVEST National Conference, New Delhi. \\
\hline 1985 & 6th INVEST National Conference, Jamshedpur. \\
\hline 1986 & The Society of Indian Value Management (SIVAM) founded in Bangalore. \\
\hline 1989 & SIVAM convenes First Value Engineering conference, Bangalore. \\
\hline 1990 & 7th INVEST National Conference, New Delhi. \\
\hline 1991 & 8th INVEST National Conference, Bombay. \\
\hline 2012 & $\begin{array}{l}2^{\text {nd }} \text { Asian Conference on Value Engineering - a key initiative by } \\
\text { Asian countries for Sustainable Growth, New Delhi. }\end{array}$ \\
\hline
\end{tabular}

Source - [7]

\subsection{VALUE ENGINEERING JOB PLAN}

Value engineering is a systematic, disciplined mechanism focused at value development. The analysis of value engineering uses a formal approach called the job plan. The job plan highlights particular strategies to evaluate a product or service successfully in order to establish the greatest number of solutions to perform the tasks needed by goods or services. Compliance to the job plan would help secure optimum advantages by ensuring more versatility.

There are numerous jobs plans available that are chosen according to the suitability of the project and specifications entitled as:

- Five Phase Job Plan (Standard)

- Six Phase Job Plan (us/epa)

- Seven Phase Job Plan

- Eight Phase Job Plan (GSA-general service administration)

VE is carried out every so often by consistently executing a multi-stage work schedule. The initial ve method was a six-step methodology known as "value analysis job plan" which was further developed and moulded with the framework of the projects that used the job plan in their execution.

The six stages job plan (information phase, function analysis phase, creative phase, evaluation phase, development phase, and presentation phase) is considered and explained briefly.

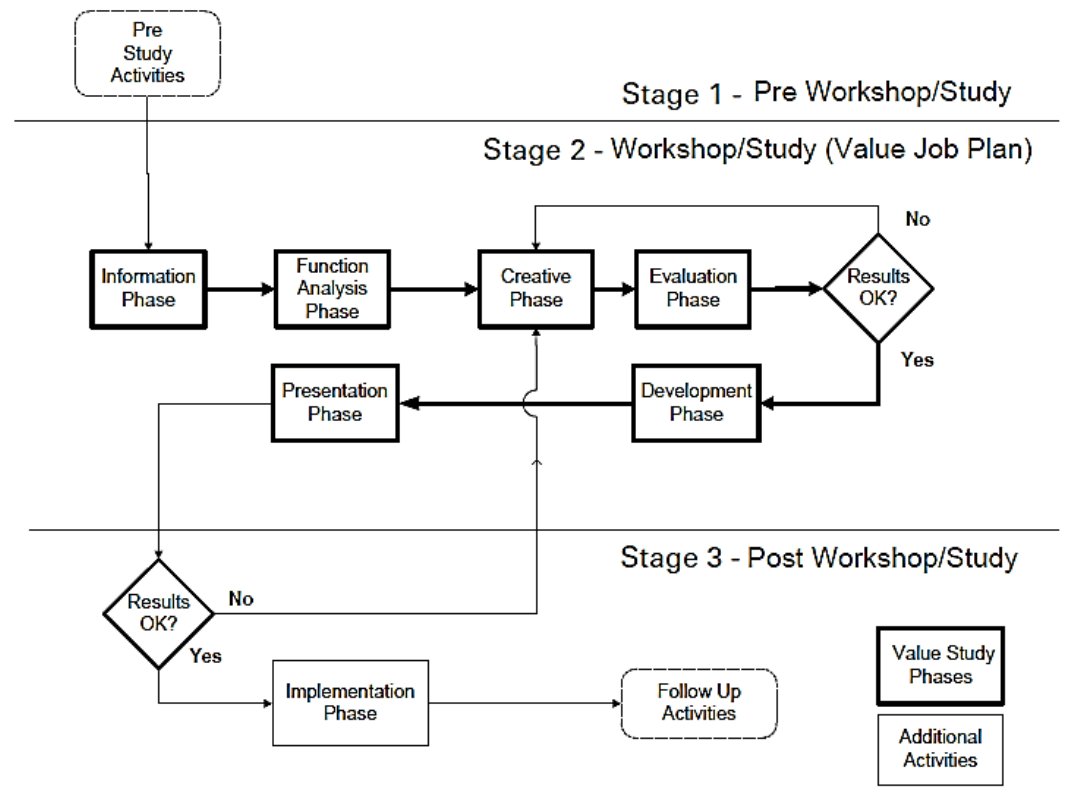

Job Plan Layout [8]

International Journal of Engineering Technologies and Management Research 
Prashant Sharma, and Dr. Ramesh Srikonda

\begin{tabular}{|c|c|c|}
\hline \multicolumn{2}{|c|}{ STAGES IN JOB PLAN } \\
\hline STAGE 1(Pre-workshop) & STAGE 2 (workshop) & STAGE 3(Post workshop) \\
\hline $\begin{array}{c}\text { Collection of user } \\
\text { Requirements }\end{array}$ & Information Phase & \\
& & \\
& $\begin{array}{c}\text { Execution of Guidelines for the Accepted Value Study } \\
\text { Collection of Information of } \\
\text { project }\end{array}$ & $\begin{array}{c}\text { Function Analysis } \\
\text { Phase }\end{array}$ \\
\cline { 1 - 1 } Identify Evaluation Criteria & Creative Phase & \\
\hline Scope of Study & Evaluation Phase & \\
\hline Build Models & Development Phase & \\
\hline Finalize Team Structure & Presentation Phase & \\
\hline
\end{tabular}

\subsubsection{WORKSHOP STAGE}

\section{Information Phase}

The purpose of the information phase is to evaluate the project's prime client preferences; identify and rate the value of project features and characteristics; and equate the project to competition or direct analogy with related projects [2]. Information for project is collected through either primary sources or secondary sources. The scope of the study is defined and further the team for value analysis study is finalised. The purpose of the information phase is to conclude the information bundle of the value analysis begun in the pre-study work. The ve implementor instruct the value analysis team if not completed during the pre-study events, providing the team with an ability to raise queries based on the data studied by them.

Information phase involves review of project; gathering background information; updating customer needs and requirements; establishing objectives and goals; defining scope; understanding current costs which include cost model and cost visibility.

\section{Function Analysis Phase}

Function analysis methods are used to describe, evaluate and understand a project's functions, how the functions contribute to each other, and what functions need attention if a project's value is to be enhanced [9]. The function can be categorised into two types which are - primary and secondary functions which help in study of function analysis. Primary function describes the main/important work of the project, process or a product that needs to be accomplished. The other tasks that the system executes and are subordinate to the basic role are secondary functions. They encourage the primary purpose and help run and market the product, service or method. Secondary functions, aesthetic or unwanted, may be required. In order to allow the primary function to occur or to occur better, certain secondary functions are important.

\section{Creative Phase}

The aim of the creative process is to produce a large number of thoughts. There is an opportunity to choose the idea(s) that best fulfills the goals of ve study by generating several ideas. There is a possibility that the proposal could not be regarded originally as a "solution" to the issue does not inhibit its placement on your list. The aim is to build a long list, not responses, of thoughts. Either of two aims fits each idea: a possible solution or a catalyst for other ideas. Very frequently, individuals only present proposals that they view as potential alternatives. In general, these "ideas" are not anything more than the conventional solutions to the dilemma.

\section{Evaluation Phase}

The intention of the evaluation process is to efficiently reduce the wide range of ideas produced during the creative phase to few proposals that seem to be convincing in achieving the goals of the project. The obvious nonsense ideas generated during creative sessions will be excluded during the assessment process, the ideas will be grouped into logical groupings, then evaluated in compliance with project requirements, and the best mix of ideas will be found. 


\section{Development Phase}

The aim of the production stage is to pick and plan the "right" alternative(s) for value enhancement. In order for the designer and owner to make an initial evaluation of their viability for execution, the information bundle prepared by the team for each of the alternatives should have as much technological, expense, and schedule data as possible.

\section{Presentation Phase}

The aim of the presentation stage is to achieve competitiveness and a dedication from the planner, project sponsor, and other management to continue to incorporate the recommendations. The ve research group provides its proposals to the decision-making body as the last task within a merit study. The team obtains either permission to continue with implementation or recommendations for additional details needed through the presentation and its engaging discussions.

\subsection{VALUE ENGINEERING APPLICABILITY}

Referring to [2], Wherever cost and/or efficiency enhancement is expected, the ve approach may be extended. In terms of monetary aspects and/or other essential considerations, such as efficiency, consistency, time, resources, environmental effect and longevity, this enhancement can be evaluated.

VE is conducted on a project-to-project basis for structural engineering work, such as houses, bridges, industrial construction, and water/sewage treatment plants, which appear to be one-time installations. Because these are onetime capital investments, it is important to apply as soon as possible early in the planning cycle to achieve optimum benefits [10].

\section{Potential Savings from Value Engineering}

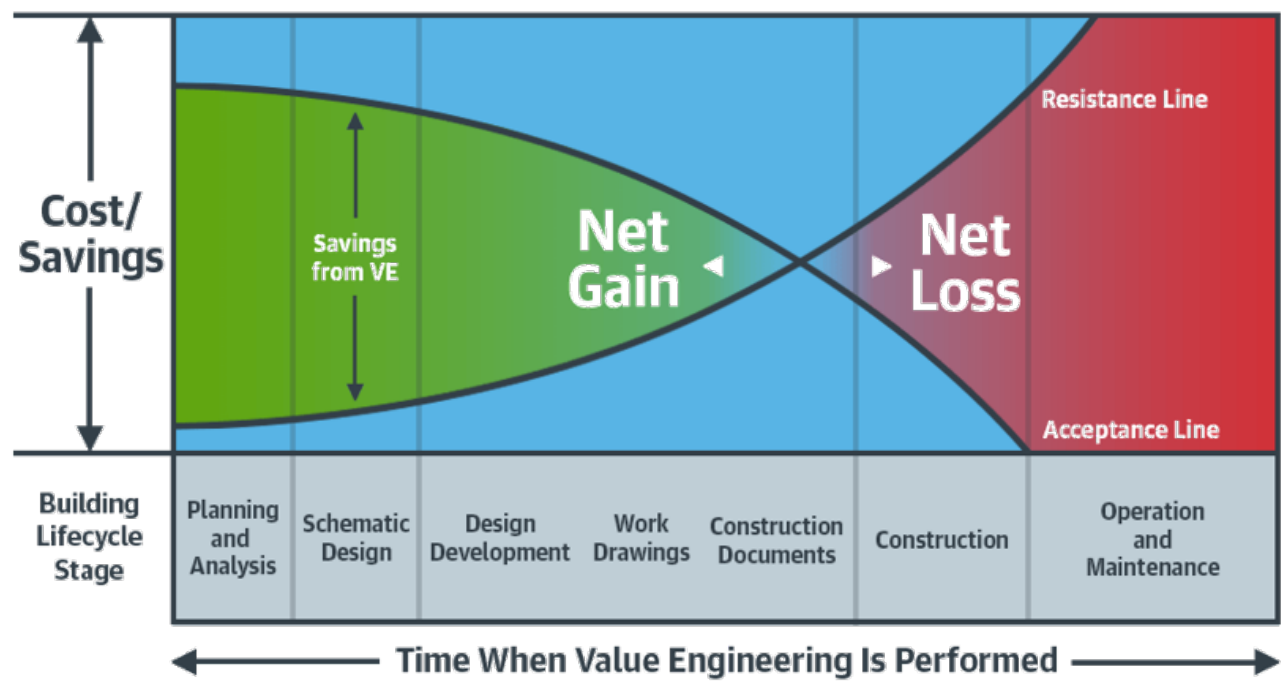

Cost/ savings vs application of ve at certain stage of project [8]

Conferring to [11] Site, electrical, HVAC, exterior walls and flooring finishes, each with more than 30 ve items and together they represent more than 50 percent of the ve items, are the top five commonly value engineered categories. Elevators, fire protection, foundations, roof opening and canopy are the five least highly valued 29 engineered categories; there were only two or three ve elements in each of these categories.

\subsection{FACTORS AFFECTING VALUE ENGINEERING APPLICABILITY}

1) Absence of rules and data.

2) Absence of learning and exercises

3) Interruption to normal work schedule 
4) Change in owners' requirements

5) Clash of priorities by multiple stakeholders of the project

6) Guidelines and practices that are obsolete

7) Repeated thought and detrimental actions

8) Absence of culture for embracing the transition

9) Over-development and extrapolation

10) Absence of interaction and bad relations

\subsection{VALUE ENGINEERING APPLICABILITY NEEDS}

1) The significance in the contract agreement of incorporating the Value Engineering change Proposals (VECP) clause.

2) Need for of the participation of certified workers in the design team for value engineering.

3) The need for experts and students to have value engineering training opportunities.

4) The need to improve students' social interaction skills during their studies.

5) The value of establishing a variety of procurement routes for projects.

6) The need for educating and making clients more demanding for value engineering.

7) Necessity of upgrading construction industry standards and specifications in the countries of the participants.

\subsection{VALUE ENGINEERING ADVANTAGES}

1) Job analysis distinctive way (function analysis).

2) A significant number of good ideas that are relevant are nominated.

3) An action plan that consists of multiple consecutive steps of a logical chain in place.

4) A multi-disciplinary unit working on common values research.

5) Ensure cooperation with the respective project authorities.

\section{METHODOLOGY}

Two case studies of different scale of housing projects are studied and look upon how the value engineering has been applied. The process of applying value engineering to the project is explained with each project.

The first step will focus on collection of data about the project, briefs and other necessary information required about the project to be reviewed and applying value engineering on the same. The next step will focus on the assessment of the various materials available to complete the job in lower cost with same functional value as conventional materials used for similar job.

According to the usage for various areas a list of best suited materials will be prepared and the cost review of the project will be done after applying the alternative materials in the project.

Based on the knowledge gained from the case studies the value engineering process will be implemented to the project and seen for the review in cost and increase in the value.

\section{CASE STUDIES}

\subsection{CASE STUDY 1}

The first case study is of a residential tower of focus infrastructure situated at Ahmedabad. The project mainly consists of 4 towers which are 7 stories high and are designed as $2 \mathrm{BHK}$ and 3BHK type flats. Two of the towers are completed i.e. A \& B towers and C \& D are still in progress. 


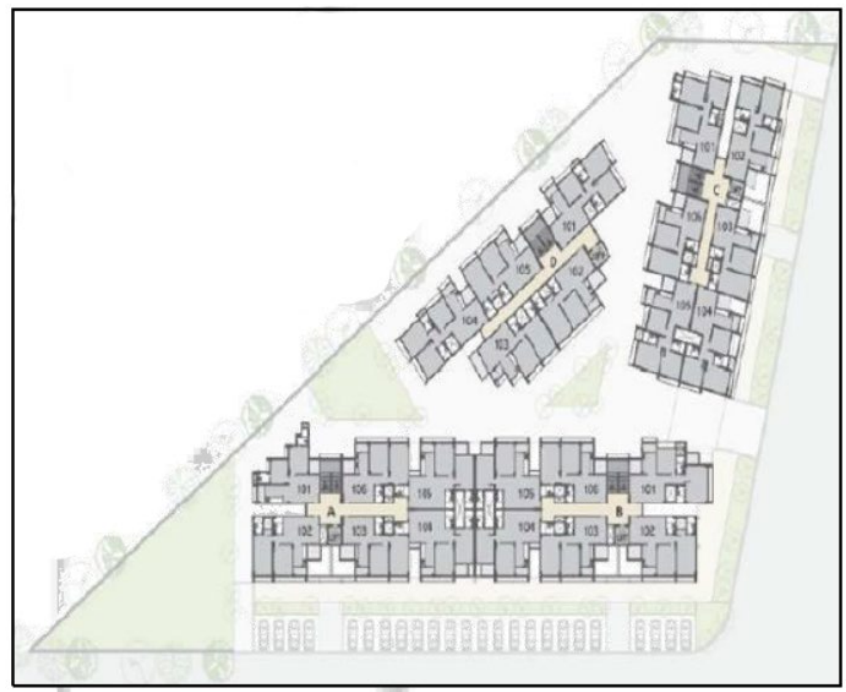

Typical layout of site plan [12]

The information regarding the project was collected by the researcher through the technical team of the project which was involved in various activities of the project.

\section{Cost Model}

To determine the cost of each function, ve team applied the uniformed cost model. It helps the team to find out the cost occurred in the overall of the project and which specific activity or sub-section is more affected and has the highest value related to other activities or material and components. The cost model is developed for this project and cost of all components has been described in it.

\begin{tabular}{|r|l|r|r|}
\hline Sr. No. & Work & Total cost (Rs) & Percentage \\
\hline & $\begin{array}{l}\text { Infrastructure } \\
1\end{array}$ & $64,75,000$ & $10.93 \%$ \\
\hline & Development & & \\
2 & Fees & $88,48,000$ & $14.98 \%$ \\
\hline 3 & Structural work & $1,18,33,188$ & $19.98 \%$ \\
\hline 4 & Masonry work & $1,13,92,518$ & $19.23 \%$ \\
\hline 5 & Electrical work & $82,85,036$ & $13.99 \%$ \\
\hline 6 & Finishing work & $1,23,97,979$ & $20.93 \%$ \\
\hline Total Project Cost & $5,92,31,721$ & $100 \%$ \\
\hline
\end{tabular}

Percentage \& cost of the work of block a [12]

In.the above table, description of major activities is listed along with the total cost of them before applying the value engineering and at the last column percentage of that work in respect to overall work.

\section{Creative Phase}

According to the cost distribution model and functional analysis, the value engineering team has to come up with alternative materials that can fulfil the requirement of the replaced material. There are so many innovative materials that, in terms of cost \& quality, would be more useful for the project. Therefore, it is an important task to come up with alternatives that are best suited and locally available. 


\section{Judgement Phase}

As referring to the cost distribution shown in above table, the super-structure cost is more as compared to others. In this site, roughly 38,250 AAC block numbers are used such that if the blocks are supplemented by other types of other bricks of the same or better consistency at less expense than it is possible, the total cost of site building will be reduced. Similarly, the road that is constructed by RCC costs more. If the RCC road is changed with paver blocks then certainly there will be a reduction in the cost while serving the same purpose.

\section{Development Phase}

After a brief brainstorming session and examining market survey, some alternative material found depending on cost, quality and availability. The alternative materials are sand blocks in place of AAC blocks, paver block roads in place of RCC roads and coupler for overlapping reinforcement in place of overlapping bars.

\section{Recommendation Phase}

The results shown in changing the above materials has a relative impact on the overall cost of the project. So, if value engineering is applied in projects, it can make more benefits in terms of saving cost, time and increasing or maintaining the same quality.

\begin{tabular}{|c|c|r|r|}
\hline Sr. No. & Replacement & Saving & $\begin{array}{l}\text { Saving in } \\
\text { Percentage }\end{array}$ \\
\hline 1 & Sand Blocks & $₹ 20,37,882$ & $78.80 \%$ \\
\hline 2 & Paver Blocks & $₹ 22,03,711$ & $19.00 \%$ \\
\hline 3 & Rebar Couplers & $₹ 2,73,570$ & $37.60 \%$ \\
\hline \multicolumn{2}{|c|}{ Total Saving } & \multicolumn{2}{|c|}{$₹ 45,15,170$} \\
\hline
\end{tabular}

Total cost reduction in the construction project [12]

\section{Conclusion}

\begin{tabular}{|c|c|c|}
\hline $\begin{array}{c}\text { Project Cost } \\
\text { before VE } \\
\text { implementation }\end{array}$ & $\begin{array}{c}\text { Project Cost after } \\
\text { VE } \\
\text { implementation }\end{array}$ & $\begin{array}{c}\text { Percentage } \\
\text { of total } \\
\text { saving }\end{array}$ \\
\hline$₹ 5,92,31,721$ & $₹ 5,47,16,558$ & $7.62 \%$ \\
\hline
\end{tabular}

Total percentage of saving cost [12]

The above case study shows that the concept of value engineering can be applied at any stage and it can reduce the cost of the project just by introducing the advanced alternate materials that are locally available thus increasing the value of the project. There is a substantial difference of $8 \%$ in the overall cost of the project after the introduction of value engineering.

\subsection{CASE STUDY 2}

The project considered for case study is a large residential project. The project consists of 6 towers with 14 floors in each tower. It is designed by JW consultancy. Due to vast construction, there is a shortage of material, time overrun which eventually led to increase in labour cost and daily resource cost. These issues were faced even with a proper planning and scheduling of material and labour. The practice of value engineering is applied on this project. After collecting the information for such large type of project, it was found that the annual cost consumption for both shuttering and labour work was very high.

\section{Proposed Alternative Function}

The first alternative that has been introduced is the mivan technology. In mivan shuttering, the casting of columns, slabs and walls are done by continuous pouring of concrete. Air curing compounds help in early removal of forms because they are made strong, sturdy and fabricated with accuracy and easily handled. These components 
are very light in weight because of aluminium and provide no of repetitions with clean and good finish which reduces the cost of plastering. The second alternative that has been introduced is usage of clc block walls instead of conventional fly ash bricks. The third alternative that has been introduced is the use of gypsum punning in place of conventional mortar plastering as it leads to loss of material and time wastage that eventually increases the cost of construction.

\section{Cost and Time Comparison}

In present case study, the mivan shuttering is used in place of conventional shuttering and its observed that the project cost has escalated 2.5 times but the overall time for this activity has reduced by $62 \%$. It is determined that mivan shuttering is more suitable for large scale projects. The initial cost for this technique is high but it can be reused for about 200-300 times also it reduces the need of plastering work because of its clean and smooth surface finish.

\begin{tabular}{|c|c|c|c|c|}
\hline $\begin{array}{c}\text { Sr } \\
\text { No }\end{array}$ & Particulars & Unit & Conventional Shuttering & $\begin{array}{c}\text { Mivan } \\
\text { Shutttering }\end{array}$ \\
\hline 1 & Material cost+Labour Cost & Sqmtr & 610 & 7750 \\
\hline 3 & Number of repetitions & & 15-20Times & $\begin{array}{c}200- \\
\text { 300Times }\end{array}$ \\
\hline 4 & $\begin{array}{c}\text { Minimum duration of slab } \\
\text { cycle }\end{array}$ & Days & 21 & 10 \\
\hline 5 & $\begin{array}{c}\text { Total Cost Per Slab } \\
=\text { Shuttering Area*Rate }\end{array}$ & Rs. & 837617.23 & 10641858.25 \\
\hline 6 & $\begin{array}{c}\text { No of days to complete } \\
\text { one tower }\end{array}$ & Days & 294 & 140 \\
\hline
\end{tabular}

Result comparison of mivan and conventional shuttering [13]

\begin{tabular}{|c|c|c|c|c|}
\hline $\begin{array}{c}\text { Brick } \\
\text { Type }\end{array}$ & Qty & Rate & Amount & $\begin{array}{c}\mathbf{1 4} \\
\text { Floors }\end{array}$ \\
\hline 4" Bricks & 64348 & 8.5 & 546958 & 7657412 \\
\hline $\begin{array}{c}\text { CLC } \\
\text { Bricks }\end{array}$ & 7831 & 72 & 563832 & 7893648 \\
\hline
\end{tabular}

Result comparison of clc blocks and conventional fly ash bricks (4") [13]

The result shows that, compared with mivan shuttering, the use of clc bricks decreases the cost and time of the project. Brick job time can be shortened by mivan, but it takes more expenditure than brickwork.

\section{Conclusion}

While mivan technology's initial investment is strong, it offers cost-effective project for large projects and decreases project time by 52 percent relative to traditional shuttering, saves daily labor and daily energy that ultimately minimize project cost. The use of clc blocks decreases building weight due to lower density and reduces construction time due to greater scale.

\section{RESULTS AND DISCUSSION}

The projects considered for case studies are housing projects of different scales. It is observed from the above case studies that the study of value engineering helped in proposing the right alternatives in terms of materials that can make an overall difference in the cost of the project. The first case study was introduced with three alternatives such as use of sand blocks in place of AAC blocks. Sand blocks showed same or better consistency at less expense plus it was a locally available material according to the location of the site. The second alternative introduced was the use of paver block road in place of RCC road. Although RCC roads are extremely stable and more environment friendly but costed more than paver block road. The third replacement introduced was the use of couplers in place 
of overlaps which provided more power and load route continuity that laps cannot provide. There was a total of $8 \%$ difference in the overall cost of project after introduction of value engineering. The practice of VE not only reduced the cost but also increased the value of the project and use of locally available material.

The second case study was introduced with two alternative such as use of Mivan shuttering in place of conventional shuttering. It was realised that with the help of Mivan shuttering the overall time project time was reduced to $52 \%$ relative to conventional shuttering. Although its initial investment is high but considering the scale of the project it was more cost effective to use it. The second alternative proposed was use of CLC blocks in place of 4 inches bricks due to its low density and it helped in reducing the overall load of the building with reducing construction time to a greater scale.

\section{CONCLUSION AND FUTURE WORK}

The requirement for affordable housing is increasing rapidly due to the growth in the urban population and the solutions such as housing schemes that are introduced by the government have a huge amount of money associated with them. To overcome such shortage and utilization of such huge capital, it becomes essential to apply construction techniques such as Value Engineering over conventional practices in these projects where factors such as cost, performance, quality, and time play a major role. The application of value engineering can help in identifying and implementing various possible creative alternatives which will result in the reduction of cost, better performance, high quality, and less project duration. The case studies mentioned above in the research shows the application of value engineering in housing projects of different scale clearly shows the impact in terms of capital saved or improved functionality or an overall reduction in project duration and therefore it can be projected how much capital and resources can be saved on such projects which can be further used in the betterment of the people by the Government.

The findings from this research will be implemented further in an EWS housing project which is proposed under any government housing scheme. The proposed methodology in this research will be applied to the project taken for study.

\section{SOURCES OF FUNDING}

This research received no specific grant from any funding agency in the public, commercial, or not-for-profit sectors.

\section{CONFLICT OF INTEREST}

The author have declared that no competing interests exist.

\section{ACKNOWLEDGMENT}

None.

\section{REFERENCES}

[1] N. Rich and M. Holweg, "Rich, BSc MBA Matthias Holweg, Dipl.- Wirtschaftsing.(FH) MSc," p. 32, 2000, [Online]. Available: https://www.urenio.org/tools/en/value_analysis.pdf.

[2] P. M. Rane, N.L., Attarde, “Application of Value Engineering in Commercial Building Projects," Int. J. Latest Trends Eng. Technol., vol. 6, no. 3, pp. 286-291, 2016.

[3] Lawrence D Miles, "Techniques of Value Analysis and Engineering by Lawrence D Miles | Decision Making | Engineering," 1972. https://www.scribd.com/doc/149390093/Techniques-of-Value-Analysis-andEngineering-by-Lawrence-D-Miles (accessed Jan. 02, 2021). 
[4] G. D. H. Larry W. Zimmerman, "Value engineering : a practical approach for owners, designers, and contractors / Larry W. Zimmerman, Glen D. Hart. - Trove,” 1982. https://trove.nla.gov.au/work/10404031 (accessed Jan. 03, 2021).

[5] Docd, "SD-24 Value Engineering : A Guidebook of Best Practices and Tools Office of Deputy Assistant Secretary of Defense Systems Engineering," 2006.

[6] A. Chougule, A. K. Gupta, and S. Patil, "Application of Value Engineering Technique to A Residential Building Case Study,” Int. J. Innov. Res. Adv. Eng., vol. 1, no. 12, pp. 115-118, 2014.

[7] P. Gohil and S. Patel, "Review of Value Engineering in Indian Construction Industry .," vol. 8, no. Iii, pp. 10801085, 2018.

[8] K. Eldash, "VALUE ENGINEERING ( Course Notes ) Table of Contents INTRODUCTION TO VALUE ANALYSIS ............................. 2 VALUE METHODOLOGY STANDARD 5 QUALITY FUNCTION DEPLOYMENT " no. February, 2015.

[9] X. Li, “Application of Value Methodology to Improve Preservation of Infrastructural Assets in Rijkswaterstaat," no. September, 2008.

[10] P. N. DELL'ISOLA AJ, “Value Engineering Cost Effectiveness. Tool for Designer Too,” Value Eng, vol. 1, no. 5, pp. 263-267, 1969.

[11] J. K. Siedel, "Value Engineering Trends in the Construction Industry," pp. 1-14, 2012.

[12] D. Parakhiya and J. Patel, "Application of Value Engineering in Construction Project: Case Study on Residential Project in Ahmedabad," Int. J. Sci. Res. Dev., vol. 5, no. 02, pp. 1890-1894, 2017, [Online]. Available: http://www.ijsrd.com/Article.php?manuscript=IJSRDV5I21756.

[13] S. S. Jadhav and P. S. D. Patil, "Implementation of Value Engineering for Residential and Commercial Buildings," no. 4, pp. 196-202, 2019. 